\title{
Review
}

\section{Structure, function and regulation of p63 and p73}

\author{
M Levrero', V De Laurenzi ${ }^{2}$, A Costanzo ${ }^{1}$, J Gong ${ }^{3}$, G Melino ${ }^{2}$ \\ and JYJ Wang*,3 \\ 1 Fondazione A. Cesalpino - University of Rome 'La Sapienza', Rome, Italy \\ 2 IDI-IRCCS Biochemistry Lab., University Tor Vergata, Rome, Italy \\ 3 Department of Biology, and the Cancer Center, University of California, San \\ Diego, La Jolla, California, CA 92093-0322, USA \\ * Corresponding author: JYJ Wang, Department of Biology, and the Cancer \\ Center, University of California, San Diego, La Jolla, California, CA 92093- \\ 0322, USA; E-mail: jywang@ucsd.edu
}

Received 30.9.99; accepted 26.10.99

Edited by R Knight

\begin{abstract}
The $\mathrm{p} 53$ tumor suppressor gene is one of the most frequently mutated genes in human cancers. ${ }^{1}$ 553 is a sequence-specific transcription factor and plays a critical role in activating the expression of genes involved in cell cycle arrest or apoptosis under conditions of genotoxic stress. ${ }^{2,3}$ For over two decades, p53 was thought to be the only gene of its kind in the vertebrate genomes. This strong conviction, which was widely accepted in the p53 field, has now been proven to be incorrect. Two genes, referred to as p63 and p73, have been found to encode proteins that share a significant amino-acid identity in the transactivation domain, the DNA binding domain, and the oligomerization domain with $\mathrm{p} 53$. In the short period since their cloning, a number of investigators have reported on the structure, the function and the regulation of $p 63$ and p73. This review summarizes the current information on the $p 63$ and the $p 73$ genes, with a focus on the differences between the three members in this newly defined p53-gene family.
\end{abstract}

Keywords: p73; p53; c-Abl; apoptosis

Abbreviations: HPV-16, human papilloma virus-16; IGFBP, Insulin-like growth factor binding proteins; IR, ionizing irradiation; MEFs, mouse embryo fibroblasts; MMS, methylmethane sulfonate; OD, oligomerization domain; SAM, sterile alpha motif; TA, transactivation domain; $\Delta \mathrm{N}$ p63, $\mathrm{N}$-terminal deleted $\mathrm{p} 63$ variants

\section{Alternative splicing of p63 and p73}

The p53 gene generates a single mRNA with a single open reading frame. In contrast, both the p63 and the p73 genes generate several differentially spliced variants. With the p73 gene, alternative splicings not only add or delete coding sequences, but also alter the reading frame. Hence, the p63 and the p73 genes can each encode several different proteins. Most notably, both the p63 and the p73 genes encode alternatively spliced C-terminal regions that are not found in the p53 protein (Figure 1).

The p63 gene encodes at least six open reading frames: from the usage of two different promoters/ATG in combination with three alternatively spliced $C$-terminal ends (Figure 1). The three isoforms (TA- $\alpha$, TA- $\beta$ and TA$\gamma)$ are produced by a 5 -promoter and alternative splicing at the $3^{\prime}$ end of the gene. These three isoforms contain the coding sequence for the $\mathrm{N}$-terminal transactivation (TA) domain. Each of these three splice variants can also be expressed from an internal promoter upstream of exon $3^{\prime}$, that provides a different ATG to initiate translation downstream of the TA domain. These $\mathrm{N}$-terminal deleted p63 isoforms are referred to as $\Delta \mathrm{N}$-alpha, $\Delta \mathrm{N}$-beta and $\Delta \mathrm{N}$ gamma. These $\Delta \mathrm{N}$ p63 isoforms do not activate transcription but instead can inhibit the transactivation functions of the full length p63 proteins and of p53. ${ }^{4}$

The p73 gene generates at least six open reading frames with alternatively spliced 3-region. Initially, two isoforms of p73 were identified: ${ }^{5}$ the full length alphaisoform and a C-terminal shortened beta-isoform resulting from the alternative splicing of exon 13. Four other spliced forms of p73 have since been identified in normal human cells. ${ }^{6-8}$ The splicing patterns for each of the isoforms are shown in Figure 1. The alpha, beta, delta and zeta isoforms share the same reading frame in the $\mathrm{C}$-terminal region. The delta-isoform lacks the majority of the C-terminal region, whereas the zeta-isoform has an internal deletion lacking amino acids $400-496$ of the alpha-isoform. The gamma isoform contains a different $\mathrm{C}$-terminal reading frame. The epsilon-isoform has a C-terminal region composed of the gamma- and then the alpha-reading frame. N-terminal deleted p73 variants, such as the $\Delta \mathrm{N}$ p63, have not been reported. Nevertheless the expression of such variants from the p73 gene cannot be ruled out at this time.

Several other spliced varinants of p73 have been reported based on detection by RT-PCR in tumor samples, but these variants have not yet been cloned. Examples of these RT-PCR products are shown in Figure 2. These additional spliced variants were mostly detected in tumor samples or in cancer-derived cell lines. A recent study of breast cancer samples and cell lines showed an increased expression of p73 protein (38\% of primary tumours and $71 \%$ of cell lines), with a complex collection of spliced variants. In contrast, normal tissues and other cancer types expressed predominantly the alpha isoform of p73. ${ }^{9}$ In another study on neuroblastoma, a p73 variant without exon 2 was detected, and such a variant would lack the transactivation domain if it was translated. ${ }^{10}$ Moreover, different patterns of splicing variants of p73 were found in different subareas of the same neuroblastoma tumor, ${ }^{10}$ indicating that the splicing pattern of p73 may reflect the 


\section{A}

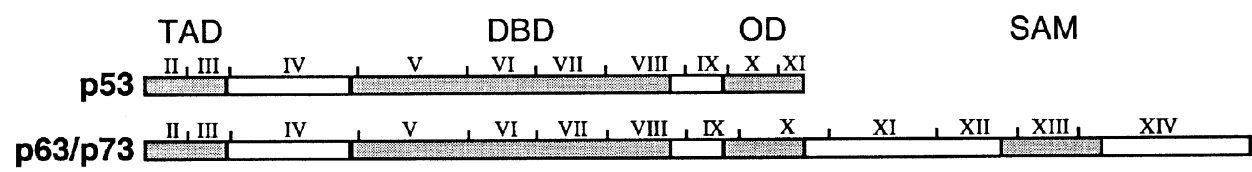

B
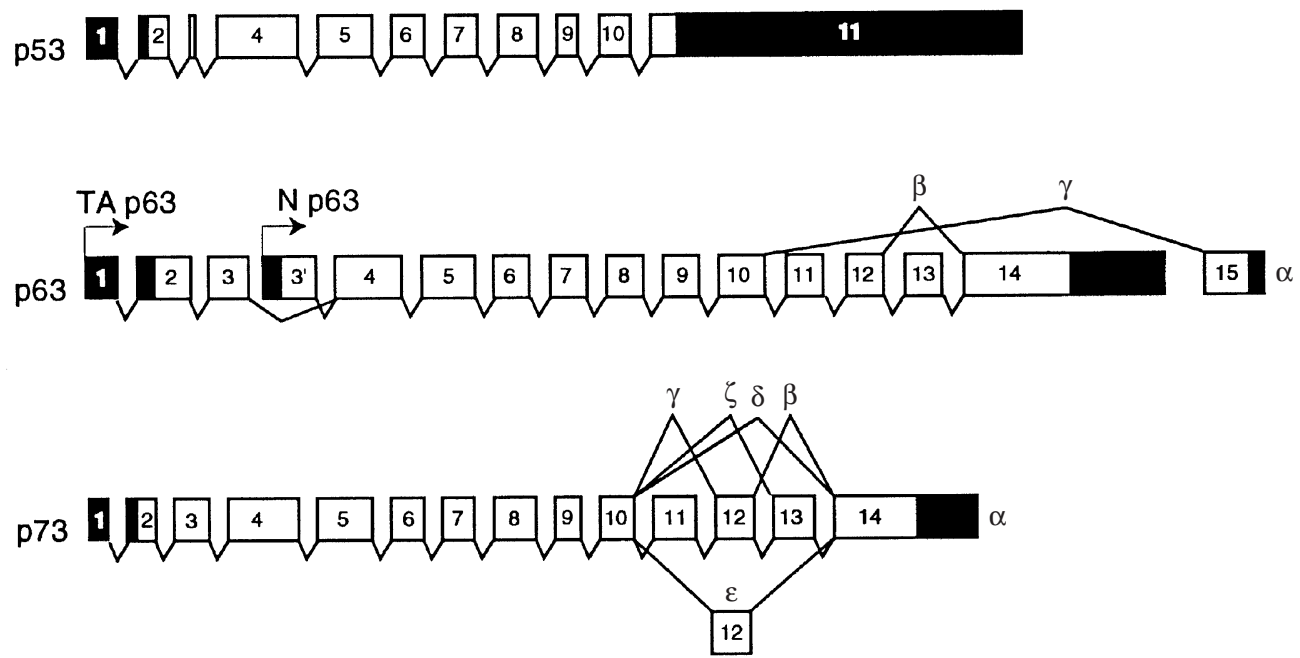

Figure 1 (A) Schematic representation of the structure of p53, p63 and p73. The transactivation domain (TAD), DNA binding domain (DBD) and the oligomerization domain (OD) are indicated in grey. The number of the exons is indicated in roman letters above each full length protein. (B) Schematic representation of genomic structure and splicing of p53, p63 and p73. Untranslated regions are in black

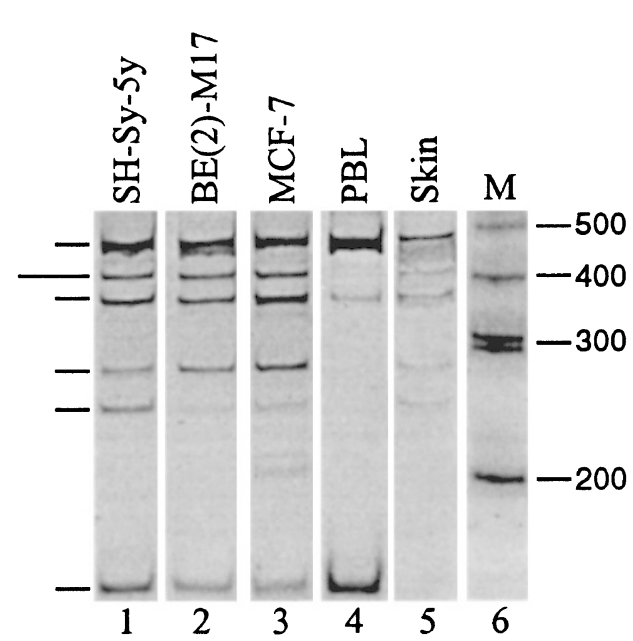

Figure 2 RT - PCR of cells expressing different isoforms of p73. Cell source is indicated; each isoform is indicated on the side. Beside the six splicing variants detected in human normal cells, cancer cells express different isoforms not yet characterized. The molecular mechanisms for this cancer instability and the function of these cancer variants is unknown. The experimental conditions are described in De Laurenzi et al. ${ }^{6,7}$ heterogeneity of the tumor. Because of this high level of heterogeneity, we have not included the splicing variants detected in cancer specimens in Figure 1.

The current information on the alternative splicing of p73 in cancer raises a number of questions, for which there are no answers at this time. What is the basis for the instability in the splicing of p73 exons in tumors? What are the functions, if any, of these different p73 isoforms in cancer development? What are the protein products, if any, of these tumor-specific p73 variants? Current commercially available antibodies only react with p73- $\alpha$ and p73- $\beta$, and these two isoforms of p73 have been detected in normal and cancer cells. The translation of the other spliced variants of p73 will have to be verified through the preparation of isoform-specific antibodies.

\section{The oligomerization domain}

The p53 protein contains an oligomerization domain (OD), which is conserved in all of the spliced variants of p63 and p73 (Figure 1). It is therefore of interest to determine if these 
family members can form hetero-oligomers. Physical interactions between p53, p63 and p73 have been investigated by in vitro assays, by the yeast two-hybrid system, or by co-immunoprecipitation in mammalian cells (Table 1). The current information suggests that the OD of each family member tends to form homo-oligomers rather than hetero-oligomers. The formation of p73 homooligomers has been shown in vitro, in yeast two-hybrid, and in mammalian cells. The formation of p63 homooligomers has been shown in vitro. In contrast, only weak heterotypic interactions could be detected either in vitro or in the two-hybrid system, and these weak interactions were not confirmed in vivo. ${ }^{6,11,12}$ Although the wild type p53 does not co-immunoprecipitate with p73, two tumor-derived p53 mutants ( $\mathrm{p} 53-\mathrm{R} 175 \mathrm{H}$ and $\mathrm{p} 53-\mathrm{R} 248 \mathrm{H}$ ) have been shown to interact with p73 and these p53 dominant negative mutants could inactivate the transactivation function of $p 73 .^{12}$ In theory, the different isoforms of p73 should be able to form mixed oligomers because they all contain the same homooligomerization domain. Given the complexity in spliced variants, oligomers of p63 or p73 could exist in a large variety of combinations. Whether these mixed oligomers exist in vivo and whether the formation of mixed oligomers affects the functions of p63 and p73 are interesting questions that await further investigation.

\section{A common domain in the $\mathrm{C}$-terminal region of p73 and p63}

The alternatively spliced C-terminal regions are likely to be the key determinants for the specialized functions of the different p63 and p73 variants. Within the C-terminal region of p63 and p73, a structure similar to the SAM (sterile alpha motif) domain has recently been identifed. ${ }^{13}$ In p73- $\alpha$, the SAM domain is composed of amino acids 487-554. The SAM domain is present in $\mathrm{p} 63$ based on sequence comparison and molecular modelling. The SAM domain is also found in the squid p53 and the rat ket gene. The squid p53 is more related to the human p73 than p53, whereas the rat ket gene is related to the human $\mathrm{p} 63$.

The SAM domain is a compact globular domain composed of five helices, of which four alpha-helices and a small $3^{10}$ helix are bundled. A consensus sequence derived from a multiple alignment of greater than 40 members of the SAM superfamily is found in p73 and p63. ${ }^{14,15}$ Canonical SAM consensus shows four predicted $\alpha$-helices (underlined):

$$
\begin{aligned}
& -1 \text { xxhxxxxxhxxWLxxhOhxxYhxxFxxxxhxx+30 residues }
\end{aligned}
$$

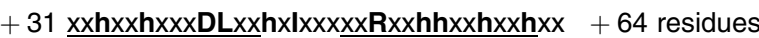

The SAM domain of p73 and p63 is most similar to that found in two tyrosine-kinase receptors: EphB2 and Eph4A. ${ }^{13}$ Some of the SAM domains have been shown to form homo- or hetero-dimers. However, the SAM domain of p73 and p63 do not form homo-dimers or hetero-dimers with each other. ${ }^{13}$ This indicates that the SAM domain of p63 and p73 may be important for interactions with other as yet unidentified proteins. Since the majority of SAM domain-containing proteins are involved in the regulation of development, p63 and p73 may also participate in the regulation of differentiation (see below).

The C-terminal region of p73 also contains an intrinsic transactivation activity, ${ }^{16}$ and this activity was lost in two p73 mutants found in neuroblastoma. Whether the transactivation function is related to the SAM domaindependent interactions is presently unknown.

\section{Genes responsive to regulation by $p 63$ and p73}

The DNA binding domain of p63 and p73 interacts with the consensus p53-responsive sequences, hence p63 and p73 proteins are likely to regulate p53-responsive genes. Indeed, p73 has been shown to activate the promoters of several p53responsive genes, including p21, bax, mdm2, cyclin-G, gadd45, IGFBP3 (A) and IGFBP3 (B) in transient cotransfection assays. ${ }^{4-6,5-17}$ Although a complete picture is still lacking, the different p73 isoforms have been reported to exhibit differential activities from various p53-responsive promoters. ${ }^{6,7,12,17-19}$ At present, there is no evidence of qualitative differences in the functional effects of the various p73 isoforms, despite the reported quantitative differences in promoter regulation. Another unresolved issue regards the ability of the different members of the p53-family to activate specific sets of target genes. In addition, it is not known whether different stimuli can selectively recruit one or more members of the p53-family to achieve specialized transcription responses. Zhu et al., ${ }^{18}$ using cell lines that inducibly over-produced either $\mathrm{p} 53, \mathrm{p} 73 \alpha$ or $\mathrm{p} 73 \beta$, have detected quantitative differences between the effects of p53 and p73 isoforms on the induction of endogenous genes such as p21, mdm2, GADD45. This study also detected genes that were selectively induced by $p 53$ but not by $p 73$. It should be noted

Table 1 Interactions between p53, p63 and p73

\begin{tabular}{|c|c|c|c|c|c|c|}
\hline & p53/p53 & p53/p73 & p53/p63 & p73/p73 & p73/p63 & p63/p63 \\
\hline $\begin{array}{l}\text { In vitro } \\
\text { Two hybrid } \\
\text { In vivo COIP } \\
\text { Reference }\end{array}$ & $\begin{array}{l}+ \\
+ \\
+\end{array}$ & $\begin{array}{c} \pm \\
\pm \\
- \\
\text { (Davison et al. } \\
\text { 1999) } \\
\text { (Di Como et al. }_{11} \\
\text { 1999) }\end{array}$ & $\begin{array}{c}-\overline{N D} \\
- \\
\text { (Davison et al., }_{1999)^{11}}\end{array}$ & $\begin{array}{c}+ \\
+ \\
+ \\
\text { (Davison et al., }_{1999)^{11}} \\
\text { (De Laurenzi et al., }_{1998)^{6}} \\
\text { (Kaghad et al., 1997) }^{5}\end{array}$ & $\begin{array}{c} \pm \\
\mathrm{ND} \\
\pm \\
\text { (Davison et al. }_{1999)^{11}}\end{array}$ & $\begin{array}{c}+ \\
\text { ND } \\
\text { ND } \\
\text { (Davison et al., }_{1999)^{11}}\end{array}$ \\
\hline
\end{tabular}

+: positive interaction; -: no interaction detected; \pm : weak interaction; ND: not determined 
that the quantitative differences reported by Zhu et al., ${ }^{18}$ in their system was not reproducibly observed by Lee and La Thangue ${ }^{19}$ in another experimental system. Nevertheless, the current data does indicate the existence of transcriptional specificity among the p53-family members and among the different isoforms of $p 73$. It would not be surprising if the transcription specificity is also determined by cell type and other physiological conditions during development.

\section{The role of $\mathrm{p73}$ in apoptosis response to DNA damage}

DNA damage inducers are known to activate p53, leading to two alternative responses: either a cell cycle arrest in $\mathrm{G} 1$ or apoptosis. Recent results have shown that DNA damaging agents also regulate the p73 protein and its function. Two types of regulation of p73 have been described: the accumulation of $\mathrm{p} 73$ protein or the tyrosine phosphorylation of p73, and these observations are summarized in Table 2. Two interesting trends have emerged from these results. First, there appears to be DNA lesion-specific regulation of $p 73$, in other words, different types of DNA damage appear to affect p73 in different ways. Second, both the accumulation of p73 and the tyrosine phosphorylation of p73 are dependent on the activation of the nuclear c-Abl tyrosine kinase.

The accumulation of p73 protein has been observed in cells treated with cisplatin, which crosslinks DNA. ${ }^{20}$ The half-life of p73 was increased by cisplatin in human colon cancer cells and in mouse embryo fibroblasts (MEFs). In both cell types, the mismatch repair protein MLH1 and the tyrosine kinase $\mathrm{c}-\mathrm{Abl}$ are required for cisplatin to induce the p73 protein. The c-Abl tyrosine kinase can prolong the halflife of $\mathrm{p} 73-\alpha, \mathrm{p} 73-\beta$ and $\mathrm{p} 73-\delta$ in transient coexpression experiments $^{20}$ (Gong J, unpublished). Unlike cisplatin ${ }^{20}$ and taxol (Costanzo A, unpublished), ultraviolet light (UV), actinomycin $\mathrm{D}$, ionizing irradiation (IR), or methylmethane sulfonate (MMS) did not induce the accumulation of p73 protein in several cell types (Table 2). Therefore, the induction of p73 accumulation does not appear to be a common response to all DNA damage inducers. Irradiation of MCF-7 cells with a high dose of IR (20 Gy) was found to induce the tyrosine phosphorylation of p73 at $2 \mathrm{~h}$ after treatment. $^{21,22}$ The $\mathrm{p} 73$ protein could be phosphorylated by the c-Abl tyrosine kinase in vitro, or under transient coexpression conditions. ${ }^{21,22}$ These results indicated that IR might induce the tyrosine phosphorylation of p73 through the activation of $\mathrm{c}-\mathrm{Abl}$ tyrosine kinase. If so, IR should not induce the tyrosine phosphorylation of p73 in c-Abl-deficient cells. However, such evidence has not been reported.

The nuclear c-Abl tyrosine kinase is activated by IR, MMS, or cisplatin, but not by UV. ${ }^{23,24}$ That UV did not affect p73 was therefore consistent with its inability to activate cAbl. The current data suggests that c-Abl can either stabilize or phosphorylate p73, dependent on the DNA damage inducers and the cell types studied. Ionizing radiation is a potent inducer of apoptosis only in some cell types (e.g., thymocytes) but not in others (e.g., fibroblasts). On the other hand, cisplatin induces apoptosis in all cell types. The kinetics of c-Abl activation by IR is rapid, occurring within 30 min of irradiation; the kinetics of c-Abl activation by cisplatin is much slower, occurring between $6-12 \mathrm{~h}$ after cisplatin addition. ${ }^{20,23,24}$ Taken together, the current data provides an interesting correlation between the kinetics of c-Abl activation and its effect on p73. Ionizing radiation activates the c-Abl tyrosine kinase rapidly and this appears to stimulate the tyrosine phosphorylation of p73 without affecting its steady state levels. It should be noted that tyrosine phosphorylation of p73 was observed at $2 \mathrm{~h}$ after IR in MCF-7 cells, at a time when cells were not undergoing apoptosis. Cisplatin

Table 2 Accumulation of p73 protein in response to drugs and radiation

\begin{tabular}{|c|c|c|c|c|c|}
\hline Cell type ${ }^{a}$ & Agents $^{b}$ & $\begin{array}{c}\text { Time }^{c} \\
\text { (h) }\end{array}$ & $\begin{array}{c}\text { Increase } \\
\text { in p73 }\end{array}$ & $\begin{array}{c}\text { Ptyr } \\
\text { in p73 }\end{array}$ & Reference \\
\hline MEF, wt & CDDP & 24 & + & ND & (Gong et al., 1999) $^{20}$ \\
\hline MEF, wt & Taxol & 48 & + & ND & Costanzo et al., unpublished \\
\hline MEF, p53-/- & CDDP & 24 & + & ND & (Gong et al., 1999) $^{20}$ \\
\hline MEF, Mlh1-/- & CDDP & 24 & - & ND & (Gong et al., 1999) $^{20}$ \\
\hline MEF, c-Abl-/- & CDDP & 24 & - & ND & (Gong et al., 1999) $^{20}$ \\
\hline MEF, c-Abl-I- & Taxol & 48 & - & ND & Costanzo et al., unpublished \\
\hline HCT116-3(6) & CDDP & $12-48$ & + & - & (Gong et al., 1999) $^{20}$ \\
\hline HCT116-2(1) & CDDP & $12-48$ & - & - & (Gong et al., 1999) $^{20}$ \\
\hline HCT116-3(6) & MMS & $0-48$ & - & ND & Gong et al., unpublished \\
\hline MCF-7 & IR & 2 & - & + & $\begin{array}{l}\text { (Agami et al., 1999) } \\
\text { (Yuan et al., 1999) }^{22}\end{array}$ \\
\hline IMR-32 & UV & 15 & - & ND & (Kaghad et al., 1997) \\
\hline IMR-32 & ActD & 2 & - & ND & (Kaghad et al., 1997) \\
\hline
\end{tabular}

aMEF: mouse embryo fibroblasts, primary cells derived from day 11-13 embryos with the indicated genotypes. HCT116-3(6) and HCT116-2(1) were derived from the colon cancer cell line HCT116 that lacks the mismatch repair gene MLH1. The MLH1 gene on human chromosome 3 was introduced into HCT116-3(6) to complement the genetic defect. A human chromosome 2 was introduced into HCT116-2(1) as a control, the MLH1 defect was not complemented in this cell line, which remains defective in mismatch repair. MCF-7 is a human breast carcinoma cell line. 3 T3 are immortalized mouse 3T3 cells. IMR-32 neuroblastoma cell line; ${ }^{b} \mathrm{CDDP}$ : ci-diam-minedichloroplatinum (II), also known as cisplatin. IR: ionizing radiation. UV: ultraviolet light ActD: actinomycin D. MMS: methylmethane sulfonate; ${ }^{\mathrm{C}}$ Time, the reported time (h) after exposure to the indicated DNA damaging agent when the cells were collected for the analyses of p73; dincrease in the steady state levels of p73 was determined by immunoblotting with anti-73 antibody ER-15. '+': increase in p73 protein; '-': no increase in p73 protein; ND: not determined; 'Ptyr: tyrosine phosphorylation of p73 was shown by immunoblotting with anti-Ptyr antibodies. '+': reactivity with anti-Ptyr antibody; '-': no reactivity with anti-Ptyr antibody; ND: not determined 
caused a protracted activation of c-Abl tyrosine kinase; this delayed activation of $\mathrm{c}-\mathrm{Abl}$ did not cause p73 to become tyrosine phosphorylated but led to a stabilization of the p73 protein at times when cells began to die. The relevance of these observations to the regulation of p73-dependent apoptosis will await further investigation.

Overproduction of $\mathrm{p} 73-\alpha$ or $\mathrm{p} 73-\beta$ can induce apoptosis in p53-deficient cells. ${ }^{17,20-22}$ While overproduction is not a physiological condition, it provides a simple assay to examine the apoptotic function of p73. Although the overproduction of p73 can kill p53-deficient cells, it did not kill c-Abl-deficient 3T3 cells. Moreover, the apoptotic function of $\mathrm{p} 73-\alpha$ or $p 73-\beta$ could be rescued by the coexpression of a wild type c-Abl tyrosine kinase. ${ }^{20-22}$ Because the c-Abl tyrosine kinase can stabilize or phosphorylate the p73 protein in transient coexpression experiments, these observations suggest that the accumulation of p73 above a threshold and/or its tyrosine phosphorylation may be required for p73 to induce apoptosis in these transient assays.

Evidence that p73 can contribute to DNA damageinduced apoptosis is provided by a link between the mismatch repair system and the induction of p73 protein. ${ }^{20}$ Mismatch repair-deficient cells are resistant to killing by cisplatin. Restoration of mismatch repair is associated with increased sensitivity to cisplatin. Gong et al., ${ }^{20}$ have shown the induction of p53 by cisplatin is not dependent on mismatch repair. In contrast, the induction of p73 protein by cisplatin is dependent on mismatch repair, not only in the colon cancer cell line HCT116, but also in mouse embryo fibroblasts. Because the mismatch repair system is required for cisplatin to activate c-Abl tyrosine kinase and to stabilize the p73 protein, the current data suggests the existence of a pathway linking mismatch repair to $c-A b l$ tyrosine kinase to $p 73$. The resistance of mismatch repair-deficient cells to cisplatin is thus correlated with their inability to activate the c-Abl/p73 apoptosis function. Precisely how the mismatch repair system activates c-Abl tyrosine kinase to stabilize p73 is currently unknown. Nevertheless, the induction of both p53 and p73 proteins appear to account for the cellular apoptosis response to cisplatin.

\section{Interaction of p73 with cellular and viral proteins}

Several recent reports have examined the regulation of $p 73-\alpha$ and $\mathrm{p} 73-\beta$ by proteins that are known to regulate p53, including Mdm2, p300/CBP and viral proteins (summarized in Tables 3 and 4). These studies have revealed interesting similarities and differences between p53 and p73. Overall, the current data is consistent with the idea that p53 and p73 may be regulated by parallel pathways that are independently regulated.

\section{Mdm2}

The p73 proteins are homologous with p53 in the $\mathrm{N}$ terminal Mdm2 binding region. Indeed, binding of Mdm2 to $\mathrm{p} 73-\alpha$ and $\mathrm{p} 73-\beta$ has been demonstrated by several independent studies. ${ }^{25-27}$ The binding of p73 to Mdm2 is shown to be mediated through the $\mathrm{N}$-terminal region homologous to p53. Therefore, alternative splicing at the C-terminal region of $p 73$ should not affect the binding of p73 isoforms to Mdm2. The p73 protein also binds to $\mathrm{MdmX}$, a protein related to $\mathrm{Mdm} 2{ }^{26}$ Binding of $\mathrm{Mdm} 2$ leads to the inactivation of the transcriptional and apoptotic functions of $\mathrm{p} 73-\alpha$ and $\mathrm{p} 73-\beta .^{27} \mathrm{Mdm} 2$ or MdmX binding, however, does not induce the rapid degradation of p73 protein. ${ }^{12,25-27}$ The p73 protein is likely to be degraded by the proteosome, because treatment of cells with inhibitors of the proteosome (LLnL and lactocystin) can cause the accumulation of p73 protein. $^{25}$ It is well established that Mdm2 can stimulate the ubiquitination of p53 and thus targets p53 for degradation by the proteosome. The accumulation of p53, induced by DNA damage, is brought about by a regulated disruption of $M d m 2 / p 53$ interaction. Since Mdm2 does not shorten the half-life of p73, which has been determined to be about $45 \mathrm{~min}$ at steady state, ${ }^{20}$ disruption of the Mdm2/p73 interaction is not likely to affect the stability of the p73 protein. The accumulation of p73 protein can be brought about by the c-Abl tyrosine kinase, which prolongs the half-life of $p 73 .{ }^{20}$ Thus, DNA damage induces the accumulation of p53 and p73 through parallel independent pathways. The accumulation of p53 is regulated by the removal of a degradationinducer (Mdm2), whereas the accumulation of p73 appears to be regulated by the activation of a stabilizer (c-Abl kinase).

Although Mdm2 does not regulate the stability of $p 73$, the interaction between Mdm2 and p73 must also be disrupted in order for p73 to stimulate transcription and activate apoptosis. This is because Mdm2 can inhibit the apoptotic functions of p73 in transient coexpression assays. $^{27}$ The interaction of p53 with Mdm2 can be disrupted through the phosphorylation of p53 at Ser15. ${ }^{28}$ Interestingly, Ser15 of p53 is not conserved in p73. At present, it is not known if c-Abl can disrupt the interaction between Mdm2 and p73. It should be noticed that c-Abl tyrosine kinase activates the apoptotic activity of p73 ( $\alpha$ and $\beta$ ) but not of $\mathrm{p} 53 .^{20}$ Whether Mdm2 participates in the regulation of p73 function under physiological conditions remains to be determined.

\section{P300/CBP}

The N-terminal region of p73, from amino acids 1-54, contains a binding site for the transcription adaptors/coactivators p300 and CBP. ${ }^{19,27}$ The $\mathrm{CH} 3$ region of $\mathrm{p} 300$, which binds $p 53$, also interacts with p73. Binding of $p 73$ to p300/CBP is required for p73 to activate transcription. The inhibition of p73 transactivating function by Mdm2 appears to be mediated by the exclusion of p300/CBP. ${ }^{27}$ These results suggest that the trans-activation function of $p 73$, like p53, is mediated by the binding of p300/CBP (Table 3). Whether the acetyltransferase activity of p300/CBP regulates, as demonstrated for $p 53$, the ability of $p 73$ to bind its cognate DNA sequences and to activate transcription is not clear at present. 


\section{Viral proteins}

The $\mathrm{p} 53$ protein is a target of several viral proteins encoded by DNA tumor viruses such as the Adenovirus, the human papilloma virus-16 (HPV-16), and the SV40 virus. Several studies have examined the interaction of $p 73$ with these viral proteins (Table 4). The HPV-16 E6 oncoprotein induces the degradation of $\mathrm{p} 53$, but $\mathrm{E} 6$ has no effect on the stability of $\mathrm{p} 73-\alpha$ or $\mathrm{p} 73-\beta .^{29,30}$ As a result, overproduction of the p73- $\beta$ protein can be achieved in E6-expressing cells and leads to growth inhibition and apoptosis. ${ }^{30}$

The SV40 T-Antigen can bind to p53, but does not interact with $p 73-\alpha$ or $p 73-\beta .^{29,31}$ The SV40 T-Antigen does not inhibit the transactivation function of $\mathrm{p} 73(\alpha$ or $\beta)$, but inhibits p53 under similar experimental conditions. A mutant T-Antigen that is localized to the cytoplasm can cause the cytoplasmic localization of p53 in transient coexpression experiments, but this mutant T-Antigen does not alter the nuclear localization of coexpressed p73 ( $\alpha$ or $\beta) .{ }^{31}$

The Adenovirus E1B $55 \mathrm{~K}$ protein also binds to p53 but does not interact with p73 ( $\alpha$ or $\beta) .{ }^{29,32,33}$ As expected, the $\mathrm{E} 1 \mathrm{~B} 55 \mathrm{~K}$ protein inhibited the transactivating function of p53 but not p73. Therefore, three viral oncoproteins known to inhibit p53, i.e., HPV-16 E6, SV40 T-Antigen and E1B55 $\mathrm{K}$, do not inhibit the function of $\mathrm{p73}$.

These results, however, do not rule out the possibility that oncogenic viruses do inactivate p73 by using other viral proteins. Indeed, the Adenovirus E4orf6 has been shown to inhibit the transactivation function of $\mathrm{p} 73 .{ }^{32,33}$ The E4orf6 protein can bind to $\mathrm{p73} \alpha$ or $\beta$ through the p73 C-terminal region common to the $\alpha$ or $\beta$ isoforms. ${ }^{32}$ The E4orf6 has been shown to bind the C-terminal domain of p53 through p53 amino acids $318-3603 .{ }^{34}$ It was therefore speculated that E4orf6 might also bind this region of $p 73 .{ }^{32}$ The E4orf6 protein can inhibit both the transactivation and the apoptotic functions of p73 ( $\alpha$ or $\beta$ ). Hence, Adenovirus can use E4orf6 to inactivate p73 function.

The inhibition of cellular p73 function may be important for Adenovirus to infect cells because the p73 protein, like p53, is upregulated upon Adenovirus infection. ${ }^{33}$ By measuring the levels of the endogenous p73 protein, Steegenga et al., ${ }^{33}$ have found that $\mathrm{E} 1 \mathrm{~A}$ or the $\mathrm{E} 1 \mathrm{~B} 55 \mathrm{~K}$ proteins can cause a large increase in the steady state levels of p73. By contrast, the small E1B protein or E6orf4 did not increase the levels of p73. The E1A and E1B $55 \mathrm{~K}$ proteins have also been shown to induce the accumulation of p53 protein. The induction of p53 by E1A may likely be mediated by the activation of p19Arf expression. The p19Arf protein can interfere with the Mdm2-mediated degradation of p53, leading to the accumulation of $p 53$ protein. ${ }^{35,36}$ The induction of p53 by the E1B $55 \mathrm{~K}$ protein is probably mediated by the downregulation of Mdm2 expression, as E1B 55K can inhibit the transactivation function of p53. Since Mdm2 does not affect the stability of $\mathrm{p} 73$, the induction of $\mathrm{p} 73$ protein by E1A or E1B 55K may be mediated by mechanisms other than those which regulate the degradation of p53 by Mdm2. Since E1A and E1B55K can induce the expression of $p 73$, the inactivation of $p 73$ by E4orf6 is likely to be important for suppressing the death of viral-infected cells. The current data is consistent with a role of p73 in the cellular response to Adenovirus. Elucidation of the interaction between p73 and Adenovirus or other DNA tumor viruses will await further investigation.

\section{Involvement of p63 and p73 in differentiation and development}

The homology between p53, p63 and p73 suggests that the products of this gene family may share similar functions as transcription factors. However, the biological functions of this family of transcription factors are likely to be distinct.

When overproduced, p73 does share with p53 the ability to activate some common target genes, leading to cell cycle arrest or inducing apoptosis..$^{5,6,17}$ Whether p73 is physiologically relevant in the induction of cell cycle arrest or apoptosis, however, is not clear. As discussed above, p73 has been linked to the cytotoxic activity of cisplatin, where the induction of p73 contributes to but does not determine the apoptotic response. ${ }^{20}$ The induction of p73 has also been observed under conditions of mitotic spindle

Table 3 Interaction between members of p53 family and cellular proteins

\begin{tabular}{|c|c|c|c|c|}
\hline & mdm2 & MDMX & p300 & c-Abl \\
\hline p53 & + & + & +1 & - \\
\hline p73 & + & + & $+^{2}$ & $+^{3}$ \\
\hline p63 & ND & ND & ND & ND \\
\hline Reference & $\begin{array}{l}\text { (Balint et al., 1999) } \\
(\text { Ongkeko et al., 1999) } \\
\left(^{26}\right. \\
(\text { Zeng et al., 1999) }\end{array}$ & $($ Ongkeko et al., 1999) & $\begin{array}{l}(\text { Lee et al., 1999) })^{19} \\
(\text { Zeng et al., 1999) }\end{array}$ & $\begin{array}{l}\text { (Agami et al., 1999) } \\
\text { (Yuan et al., 1999) } \\
\text { (Gong et al., unpublished) }\end{array}$ \\
\hline
\end{tabular}

${ }^{\mathrm{a}} \mathrm{CH} 1$ and $\mathrm{CH} 3$ domain of p300 with $\mathrm{N}$-terminal domain of p53; ${ }^{\mathrm{b}} \mathrm{CH} 3$ domain of p300 with $\mathrm{N}$-terminal domain of p73; ${ }^{\mathrm{S}} \mathrm{SH} 3$ domain of c-Abl with Tetramerization domain of p73 (PAVP motif of p73 a.a.335-338). +: positive interaction; - : no interaction detected; ND: not determined

Table 4 Interaction between members of p53 family and viral proteins

\begin{tabular}{|c|c|c|c|c|}
\hline & HPV16 E6 & SV40 TAg & Ad. E1B 55K & Ad. E4 orf6 \\
\hline p53 & + & + & + & +1 \\
\hline p73 & - & - & - & $+^{2}$ \\
\hline Reference & $\begin{array}{l}\text { (Marin et al., 1998) } \\
\text { (Prabhu et al., 1998) }^{30}\end{array}$ & $\begin{array}{l}\text { (Marin et al., 1998) }^{29} \\
\text { (Dobbelstein et al., 1998) }^{31}\end{array}$ & $\begin{array}{l}\text { (Higashino et al., 1998) } \\
\text { (Steegenga et al., 1999) }^{33}\end{array}$ & $\begin{array}{l}\text { (Higashino et al., 1998) } \\
\text { (Dobner et al., 1996) }\end{array}$ \\
\hline
\end{tabular}

${ }^{1}$ C-terminal region common to $\mathrm{p} 73 \alpha$ and $\mathrm{p} 73 \beta ;{ }^{2}$ a.a. $318-360$ of $\mathrm{p} 53 .+$ +: positive interaction; - : no interaction detected 
defects (Costanzo A, unpublished). Under these conditions, however, p73 does not appear to contribute to apoptosis. Despite the original hypothesis that p73 is a tumor suppressor gene that is lost in neuroblastoma, there is little evidence for p73 mutations in human cancer ${ }^{37-39}$ (see also the companion review by lkawa et al.). ${ }^{40}$ Thus, p73 may not play a role similar to p53 in the development of cancer.

An important line of evidence supporting biological distinctions among the p53-family members has come from genetic analyses in mice. The p53-null mice develop normally but develop multiple types of tumors with a much higher frequency than their wild type counterparts. Cells derived from the p53-null mice are also defective in cell cycle checkpoint responses and in the apoptotic response to DNA damage. In contrast, the p63-deficient mutant mice did not show any defect related to spontaneous or X-ray-induced apoptosis during embryogenesis. Instead, the p63-deficient mice exhibited phenotypes related to abnormal differentiation. The p63-deficient mice cannot maintain the apical ectodermal ridge essential to limb development and thus have truncated limbs. They also showed defective epidermal differentiation with no hair follicles, no teeth, no mammary, lachrymal or salivary glands. ${ }^{41,42}$ The phenotypes of p63deficient mice suggest that the primary biological function of p63-encoded proteins is to regulate development. In keeping with this, we have found that the ectopic expression of p63 in normal human epidermal keratinocytes leads to the upregulation of specific markers, such as loricrin involucrin and transglutaminase 1, associated with keratinocyte differentiation (De Laurenzi V, unpublished).

The p73-encoded products may also regulate development. The p73 gene is mapped to human chromosome 1p36.33, which is frequently deleted in neuroblastomas. ${ }^{43}$ The deletion of the p73 gene in neuroblastomas suggests that loss or altered expression of p73 could be a determinant for the de-differentiated phenotype found with neuroblastoma cells. Consistent with this idea, we have found that the ectopic expression of p73 into normal human keratinocytes induces the expression of the same marker genes as p63. Moreover, the promoters of loricrin, involucrin and transglutaminase 1 are activated by exogenously expressed p63 or p73 (De Laurenzi V, unpublished). Future work in other cellular differentiation systems will help to clarify how p63 and p73 may play a role in differentiation, and what physiological signals may utilize $p 63$ and $p 73$ to regulate the developmental programs.

\section{Summary}

The p53 gene has been under intense scrutiny by the biomedical research community for a decade. The recent identification of p53-related genes has had several important impacts on our view of $p 53$. The p53-gene family is conserved through evoluation, as evident by the p73-related gene in squid. Because this family of transcription factors bind to similar DNA sequences, and because p63 has been shown to be essential in specific developmental processes, the p53 protein might also participate in developmental regulation in ways yet to be discovered (Figure 3). The current information suggests that members of the p53-family of transcription factors have overlapping as well as distinct biological functions. Although both p53 and p73 are induced by cisplatin, each is induced by distinct mechanisms through different signaling pathways activated by cisplatin. That the different members of this gene family are regulated by distinct mechanisms provides the basis

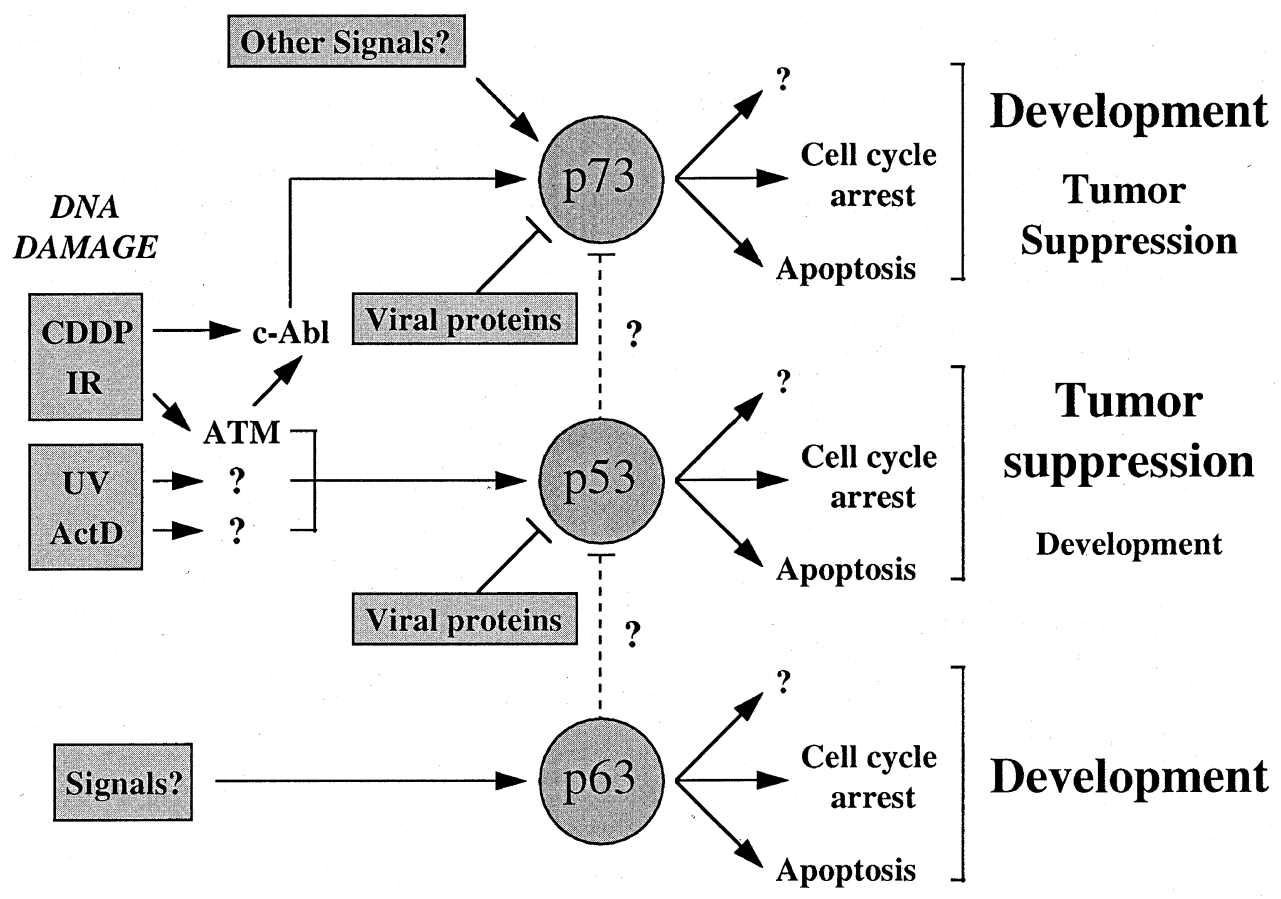

Figure 3 Schematic representation of the different regulation mechanisms and of the different biological functions of the p53 gene family 
for their distinct biological effects (Figure 3). The combinatorial regulation of the p53-family of genes may ultimately determine the transcription and biological response under conditions of differentiation or stress.

\section{Acknowledgements}

The work was in part supported by grants Telethon-E872, AIRC, MURST$40 \%$, Min Sanit, Assoc Neuroblastoma to G Melino by grants Telethon A72, AIRC, MURST-Ex40\%, ISS to M Levrero, and by grants from the National Cancer Institute, USA, to JYJ Wang.

\section{References}

1. Hollstein M, Sidransky D and Vogelstein CC (1991) p53 mutations in human cancers. Science 253: 49-53

2. Ko LJ and Prives C (1996) p53: puzzle and paradigm. Genes Dev. 10: $1054-$ 1072

3. Choisy-Rossi C and Yonish-Rouach E (1998) Apoptosis and the cell cycle: the p53 connection. Cell Death Differ. 5: 129-131

4. Yang A, Kaghad M, Wang Y, GillettE, Fleming MD, Dotsch V, Andrews NC, Caput D, McKeon F (1998) p63, a p53 homolog at 3q27-29, encodes multiple products with transactivating, death-inducing, and dominant-negative activities. Mol. Cell 2: $305-316$

5. Kaghad M, Bonnet H, Yang A, CreacierL, Biscan JC, Valent A, Minty A, Chalon P, Lellas JM, Dumont X, Ferrara P, McKeon F and Caput D (1997) Monoallelically expressed gene related to $p 53$ at $1 p 36$, a region frequentely deleted in neuroblastoma and other human cancers. Cell 90: 809-819

6. De Laurenzi V, Costanzo A, Barcaroli D, Terrinoni A, Falco M, AnnicchiaricoPetruzzelli M, Levrero M and Melino G (1998) Two new p73 splice variants, gamma and delta, with different transcriptional activity. J. Exp. Med. 188: 17631768

7. De Laurenzi V, Catani MV, Costanzo A, Terrinoni A, Corazzari M, Levrero M, Knight RA and Melino G (1999) Additional complexity in p73: induction by mitogens in lymphoid cells and identification of two new splicing variants epsilon and zeta. Cell Death Differ. 6: 389-390

8. Ueda Y, Hijikata M, Takagi S, Chiba T, Shimotohno K (1999) New p73 variants with altered C-terminal structures have varied transcriptional activities. Oncogene 18: 4993-4998

9. Zaika AI, Kovalev S, Marchenko ND and Moll UM (1999) Overexpression of the wild type p73 gene in breast cancer tissues and cell lines. Cancer Res. 59: 32573263

10. Casciano I, Ponzoni M, Cunsolo C, Tonini G, Romani M (1999) Different p73 splicing variants are expressed in distinct tumour areas of a multifocal neuroblastoma. Cell Death Differ. 6: 391-393

11. Davison TS, Vagner C, Kaghad M, Ayed A, Caput D, Arrowsmith CH (1999) p73 and p63 are homotetramers capable of weak heterotypic interactions with each other but not with p53. J. Biol. Chem. 274: 18709-18714

12. Di Como CJ, Gaiddon C and Prives C (1999) p73 function is inhibited by tumorderived p53 mutants in mammalian cells. Mol. Cell. Biol. 19: 1438-1449

13. Chi S-W, Ayeda A and Arrowsmith CH (1999) Solution structure of a conserved $\mathrm{C}$-terminal domain of $\mathrm{p} 73$ with structural homology to the SAM domain. EMBO J. 18: $4438-4445$

14. Schultz J, Pointing CP, Hofman Kand Bork P (1997) SAM as a protein interaction domain involved in developmental regulation. Protein Sci. 6: 249-253

15. Bork $P$, Koonin EV (1998) Predicting functions from protein sequences - where are the bottlenecks? Nature Genetics 18: 313-318

16. Takada N, Ozaki T, Ichimiya S, Todo Sand Nakagawara A (1999) Identification of a transactivation activity in the $\mathrm{COOH}$-terminal region of $\mathrm{p} 73$ which is impaired in the naturally occurring mutants found in human neuroblastomas. Cancer Res. 59: $2810-2814$

17. Jost CA, Marin MC and Kaelin Jr WG (1997) p73 is a human p53 related protein that can induce apoptosis. Nature 389: 191-194

18. Zhu J, Jiang J, Zhou W, Chen X (1998) The potential tumor suppressor p73 differentially regulates cellular $p 53$ target genes. Cancer Res. 58: 5061-5065
19. Lee CW and La Thangue NB (1999) Promoter specificity and stability control of the p53-related protein p73. Oncogene 18: 44171-44181

20. Gong JG, Costanzo A, Tamg HQ, Melino G, Kaelin WG, Levrero MandWang JYJ (1999) The tyrosine kinase c-Abl regulates $p 73$ in apoptotic response to cisplatininduced DNA damage. Nature 399: 806-809

21. Agami R, Blandino G, Oren M, Shaul Y (1999) Interaction of c-Abl and p73a and their collaboration to induce apoptosis. Nature 399: 809-813

22. Yuan ZM, Shioya H, Ishiko T, Sun X, Gu J, Huang YY, Lu H, Kharbanda S, Weichselbaum $R$ and Kufe D (1999) p73 is regulated by tyrosine kinase c-Abl in the apoptotic response to DNA damage. Nature 399: 814-817

23. Liu ZG, Baskaran R, Lea-Chou ET, Wood LD, Chen Y, Karin M and Wang JY (1996) Three distinct signalling responses by murine fibroblasts to genotoxic stress. Nature 384: 273-276

24. Baskaran R, Wood LD, Whitaker LL, Canman CE, Morgan SE, Xu Y, Barlow C, Baltimore D, Wynshaw-Boris A, Kastan MB and Wang JY (1997) Ataxia telangiectasia mutant protein activates $\mathrm{c}-\mathrm{Abl}$ tyrosine kinase in response to ionizing radiation. Nature $387: 516-519$

25. Balint E, Bates S, Vousden KH (1999) Mdm2 binds p73 alpha without targeting degradation. Oncogene 18: 3923-3929

26. Ongkeko WM, Wang XQ, Siu WY, Lau AW, Yamashita K, Harris AL, Cox LS, PoonRY (1999) MDM2 and MDMX bind and stabilize the p53-related protein p73. Curr. Biol. 12: 829-832

27. Zeng X, Chen L, Jost CA, Maya R, Keller D, Wang X, Kaelin JrWG, Oren M, Chen J, Lu H (1999) MDM2 suppresses p73 function without promoting p73 degradation. Mol. Cell. Biol. 5, 3257-3266

28. Prives $C$ and Hall PA. (1999) The $p 53$ pathway. J. Pathol. 187: 112-126

29. Marin MC, Jost CA, Irwin MS, DeCaprio JA, Caput D and Kaelin Jr WG (1998) Viral oncoproteins discriminate between p53 and the p53homolog p73. Mol. Cell. Biol. 18: 6316-6324

30. Prabhu NS, Somasundaram K, Satyamoorthy K, Herlyn M, El-Deiry WS (1998) p73beta, unlike p53, suppresses growth and induces apoptosis of human papillomavirus E6-expressing cancer cells Int. J. Oncol. 13: 5-9

31. Dobbelstein M and Roth J (1998) The large T antigen of simian virus 40 binds and inactivates p53 but not p73. J. Gen. Virol. 79: 3079-3083

32. Higashino F, Pipas JM and Shenk T (1998) Adenovirus E4orf6 oncoprotein modulates the function of the p53-related protein, p73. Proc. Natl. Acad. Sci. USA 95: $15683-15687$

33. Steegenga WT, Shvarts A, Riteco N, Bos JL, Jochemsen AG (1999) Distinct regulation of $\mathrm{p} 53$ and $\mathrm{p} 73$ activity by adenovirus $\mathrm{E} 1 \mathrm{~A}, \mathrm{E} 1 \mathrm{~B}$, and $\mathrm{E} 4$ orf 6 proteins. Mol. Cell. Biol. 19: 3885-3894

34. Dobner T, Horikoshi N, Rubenwolf S, Shenk T (1996) Blockage by adenovirus E4orf6 of transcriptional activation by the p53 tumor suppressor. Science 272 : $1470-1473$

35. Tao W and Levine AJ (1999) P19(ARF) stabilizes p53 by blocking nucleocytoplasmic shuttling of Mdm2. Proc. Natl. Acad. Sci. USA 96: 6937-6941

36. Zhang Y and Xiong Y (1999) Mutations in human ARF exon 2 disrupt its nucleolar localization and impair its ability to block nuclear export of MDM2 and p53. Mol. Cell 5: 579-591

37. Nimura $Y$, Mihara M, Ichimiya S, Sakiyama S, Seki N, Ohira M, Nomura N, Fujimori M, Adachi W, Amano J, He M, Ping YM and Nakagawara A (1998) p73, a gene related to $\mathrm{p53}$, is not mutated in esophageal carcinomas. Int. J. Cancer 78: $437-440$

38. Nomoto S, Haruki N, Kondo M, Konishi H, Takahashi T, Takahashi T and Takahashi T (1998) Search for mutations and examination of allelic expression imbalance of the p73 gene at 1 p36.33 in human lung cancers. Cancer Res. 58, $1380-1383$

39. Tsao H, Zhang X, Majewski $P$ and Haluska F (1999) Mutational and expression analysis of the p73 gene in melanoma cell lines. Cancer Res. 59: 172-174

40. Ikawa S, Nakagawara A, Ikawa Y (1999) p53 family genes: structural comparison, expression and mutation. Cell Death Differ. 6: 1154-1161

41. Mills AA, Zheng B, Wang XJ, Vogel H, Roop DR and Bradley A(1999) p63 is ap53 homologue required for limb and epidermal morphogenesis. Nature 398: $708-$ 713

42. Yang A, Kaghad M, Wang Y, Gillett E, Fleming MD, Doetsch V, Andrews NC, Caput $D$ and McKeon $F$ (1999) p63 is essential for regenerative proliferation in limb, craniofacial and epithelial development. Nature 398: 714-718

43. Brodeur GM, Sekhon G and Goldestein MN (1977) Chromosomal aberrations in human neuroblastomas. Cancer 40: 2256-2263 